Running head: Sensory stimulation of swallowing measured by HRM

\title{
Impact of sensory stimulation on pharyngo-esophageal swallowing biomechanics in adults with dysphagia: a high resolution manometry study
}

Financial support: none

Key words: dysphagia; swallowing; sensory stimulation; pharyngeal high resolution manometry; deglutition; deglutition disorders. 


\section{Abstract}

Purpose: Evidence supporting sensory stimulation of swallowing is based mostly on videofluoroscopy and provides little insight into changes to swallowing physiology. In this study, the impact of sensory stimulation on pharyngo-esophageal swallowing biomechanics was investigated in adults with dysphagia using pharyngeal high resolution manometry.

Method(s): Fifteen adults (8 males; $45-86$ years) with mixed etiology dysphagia were consecutively recruited over a three-month period. PHRM equipment with a $4.2 \mathrm{~mm}$ pressure catheter was used. The protocol included duplicate $10 \mathrm{ml}$ neutral, sour, cold and carbonated liquid swallows in randomized order. Semi-automated analysis was completed using an online portal (www.swallowgateway.com).

Result(s): Data from 98/120 swallows were analyzed. During the pharyngeal phase, mean pharyngeal contractile integral $(\mathrm{PhCl})$ increased significantly with cold $(\mathrm{p}=0.03)$, sour $(p=0.00)$ and carbonation $(p=0.02)$. Mean velopharyngeal contractile integral $(\mathrm{VCl})$ $(p=0.01)$ and mesopharyngeal contractile integral $(M C l)(p=0.04)$ both increased significantly with carbonation. Mean hypopharyngeal contractile integral (HPCl) was not significantly altered by sensory stimulation. Regarding UES opening, UES relaxation time (UESRT) increased significantly with cold $(p=0.032)$, carbonation $(p=0.032)$, and sour $(p=0.027)$. Extent of UES opening as measured by IRP reduced significantly with cold stimulation (9.34 to $5.17 \mathrm{mmHg})(p=0.032)$. No significant changes were observed to UES basal pressure or UES peak pressure with sensory stimulation.

Conclusions: Sensory stimulation induced biomechanical changes to pharyngeal contraction vigor, UES relaxation time and extent of UES opening during swallowing in 
adults with dysphagia. This study contributes evidence to support sensory stimulation as a dysphagia intervention. Further combined pressure impedance studies in homogeneous clinical populations are ongoing. 


\section{Introduction}

High-resolution manometry $(\mathrm{HRM})$ is a novel pressure evaluation which has evolved from traditional water perfused manometry. It involves use of a pressure catheter with 10 to 36 circumferential or unidirectional pressure sensors spaced one centimeter apart, creating dense pressure profiles of the esophagus (1). Pressure data obtained can be used to create easy to interpret color contour Clouse plots which have transformed HRM interpretation. Pharyngeal HRM (PHRM) is a technology used to evaluate oropharyngeal swallowing physiology. It provides quantitative data not available from videofluoroscopy (VFS) or fiberoptic endoscopic evaluation of swallowing (FEES) which provides new insight into swallowing pathophysiology which may contribute valuable information to advance dysphagia treatment.

PHRM can be combined with impedance (PHRIM) to analyze bolus flow in response to pressure changes during swallowing (2). Pressure-flow data has been used to create useful algorithms and classification models which have been found to predict aspiration status and pharyngeal residue during VFS $(2,3)$. An international PHRM working group recently established consensus on PHRIM methodology, protocol and outcome metrics to guide international research and practice (4).

Most PHR(I)M research to date has focused on the effects of bolus volume and

viscosity (5-7) and effects of postures and maneuvers on swallowing (8-10). Sensory stimulation (also termed sensory enhancement) is a dysphagia intervention which involves increasing sensory information within a bolus to enhance oropharyngeal swallowing. There is preliminary evidence to support the use of a cold, sour and carbonated bolus to optimize swallowing. However, most research to date focuses on 
swallow safety and efficiency as well as temporal swallowing measures based on VFS (11-15). While VFS can provide some objective swallowing measures, it requires radiology and barium has been found to suppress taste intensity and palatability (16).

PHRM can provide valuable quantitative measures of pharyngeal pressure and UES opening during swallowing. However, no studies to date have used PHRM to investigate the physiological effects of sensory stimulation on swallowing in adults with dysphagia. This study aimed to investigate if PHRM can provide novel quantitative information on the effects of sensory stimulation on pharyngo-esophageal swallowing physiology in adults with dysphagia. Previous research has demonstrated that increasing sensory input via the cranial nerves through the central pattern generator (CPG) to the nucleus tractus solitarius (NTS) in the brainstem can modify the efferent motor swallow response (17). Based on this principle, it was hypothesized that sensory stimulation could increase pharyngeal contraction vigor and UES opening during swallowing.

\section{Methods}

Ethical approval was obtained from St. James' Tallaght Research Ethics Committee (JREC). Participants were recruited using convenience sampling. Patients with dysphagia who were attending an outpatient dysphagia clinic in an acute hospital setting were invited to participate. Inclusion criteria included presence of dysphagia (minimum Functional Oral Intake Score $(18)<6$ ) and a recent VFS. Exclusion criteria included pharyngeal or esophageal diverticulum, recent nasal surgery, tracheostomy and head and neck cancer.

\section{Equipment}


A 4.2mm diameter solid state catheter with 36 circumferential pressure sensors spaced $1 \mathrm{~cm}$ apart was used for all trials (Manoscan, Medtronic, Atlanta, GA). Before each evaluation, the transducers were calibrated at 0 and $300 \mathrm{mmHg}$ using externally applied pressure. Thermal compensation on the catheter was completed according to manufacturer's guidelines.

\section{Protocol}

Patients were fasting for a minimum period of 4 hours before the examination. All participants were seated upright in a chair with head in neutral position in a quiet clinic room. The researcher had certified training in HRM and had over five years clinical experience using HRM. Optilube lubricant was applied to the distal tip of the HRM catheter. Topical nasal anesthesia (TNA) was not used in this protocol in case it altered oro-pharyngeal sensation. Previous research has found that use of TNA during PHRM did not alter perceived comfort levels (19). The catheter was inserted trans-nasally by the researcher through the participants more patent nasal cavity. Participants were instructed to swallow water via a straw while the catheter was passed through UES. The screen was observed to ensure pharyngo-UES region was straddled by sensors before the catheter was taped into position. A 5-minute accommodation period was observed to normalize pressures in pharynx and UES.

After the accommodation period, the study protocol included duplicate $10 \mathrm{ml}$ baseline liquids, cold liquids, sour liquids, and carbonated liquids. The cold bolus consisted of a commercial still water beverage (Ballygowan ${ }^{\circledR}$ still water) which was 3-5 degrees Celsius immediately preceding administration as measured by a handheld thermometer. The sour bolus was prepared by adding $10 \mathrm{ml} \mathrm{Jif}{ }^{\circledR}$ lemon juice to $50 \mathrm{ml}$ Ballygowan ${ }^{\circledR}$ still 
water (20-23 degrees Celsius). The carbonated bolus was a commercial carbonated beverage (Ballygowan ${ }^{\circledR}$ sparkling water; calcium content $\left.114 \mathrm{mg} / \mathrm{l}\right)$. It was opened and poured from a $500 \mathrm{ml}$ commercial bottle maximum 30 seconds before administration and the temperature of this bolus was between $20-23$ degrees Celsius. Before each examination, the order of each bolus was randomized using a randomization table. Each bolus was administered to participants via a $20 \mathrm{ml}$ syringe. There was a minimum 30 second time-period between swallows. A technical expert labelled swallows during the procedure. Once the protocol was completed, the catheter was removed, and the procedure was finished.

Study outcome measures were (i) adverse events (epistaxis, vasovagal event; nausea or vomiting; perforation) and (ii) protocol completion rate (\%). To evaluate the effects of sensory stimulation on the pharyngeal phase of swallowing, pharyngeal occlusive pressure measures selected. These were the velopharyngeal contractile integral ( $\mathrm{VCl})$, mesopharyngeal contractile integral $(\mathrm{MCl})$, hypopharyngeal contractile integral $(\mathrm{HPCl})$ and the Pharyngeal Contractile Integral $(\mathrm{PhCl})$. The $\mathrm{PhCl}$ is a global measure of pharyngeal contraction vigor which has also been associated with pharyngeal swallow impairment and aspiration during VFS (20). To evaluate the impact of sensory stimulation on UES opening during swallowing, measures selected were UES relaxation time (UESRT) (mmHg), UES Integrated Relaxation Pressure (IRP) (mmHg), UES Basal Pressure (UESBP) (mmHg) and UES post-deglutitive Peak Pressure (PeakP) (mmHg). These pharyngo-esophageal metrics are in line with International High Resolution Pharyngeal Manometry Working Group recommendations (4) and are defined in Table 1. 


\section{Table 1 here}

Data Analysis

PHRM data was uploaded onto an online semi-automated analysis portal (swallowgateway.com) commonly used in PHRM research (21). This portal has been proven to have excellent inter- and intra-rater reliability $(22,23)$. Once the data was uploaded, labelled swallows were identified, and six landmarks were created leading to outcomes being generated. Where participants coughed post swallow or completed piecemeal swallows per bolus, data was deleted from analysis as the correct swallow could not be selected without impedance data.

Statistical Analysis

A statistics package (IBM Statistical Package for the Social Sciences for Windows, version 25.0; IBM, Chicago, Illinois). HRM data was normally distributed, therefore parametric testing performed. Parametric data expressed as mean $+/$ - standard error and pairwise comparisons completed. A probability of $5 \%$ was taken to indicate a statistically significant difference with confidence intervals of $95 \%$ in all tests.

\section{Results}

\section{Table 2 here}

Fifteen participants met inclusion criteria and were recruited over a three-month period. Participants included eight males and seven females with dysphagia. Mean age was 63 years (age range $45-86$ years). Diagnoses and dysphagia severity as measured by the Functional Oral Intake Scale (18) are captured in Table 2. 
Intubation rate was $100 \%$ and protocol completion rate was $82 \%$ (98/120 swallows were selected for analysis). Twenty-two of one-hundred and twenty swallows from five participants ( $10 \times$ cold bolus; $8 \times$ carbonated and $4 \times$ sour) could not be analyzed either due to prolonged coughing (10/22) or piecemeal swallowing (12/22). Piecemeal swallows were excluded as the swallow containing the bolus material could not be selected for analysis without impedance measures. No adverse events (epistaxis, vasovagal event; nausea or vomiting; perforation) occurred.

\section{Impact of Sensory Stimulation on PHRM Measures}

\section{Table 3 here}

\section{Cold Stimulation}

During the pharyngeal phase, cold stimulation increased global pharyngeal function as measured by the pharyngeal contractile integral $(\mathrm{PhCl})$ from $148.11 \mathrm{mmHg} . \mathrm{cm} . \mathrm{sec}$ to 192.12mmHg.cm.sec $(p=0.025 ; 95 \% \mathrm{Cl},-84.24--6.44)$ (Table 3). There were no significant alterations to $\mathrm{VCl}, \mathrm{MCl}$ or $\mathrm{HPCl}$ (Table 3).

As regards UES opening, a cold bolus significantly increased mean duration of UES opening (UESRT) from 0.58 secs $( \pm .18)$ to 0.69 secs during swallowing on $10 \mathrm{ml}$ fluids $(\mathrm{p}=0.041 ; 95 \% \mathrm{Cl},-.21$ to -.01$)$. The cold bolus also significantly reduced extent of UES opening during swallowing as measured by IRP from $9.34 \mathrm{mmHg}$ to $5.17 \mathrm{mmHg}$ $(p=0.032 ; 95 \% \mathrm{Cl}, 0.39-7.97)$. No significant alterations to UESBP or UES Peak P were observed with a cold bolus (Table 4). 


\section{Sour Stimulation}

During the pharyngeal phase, baseline global pharyngeal function (148.11mmHg.cm.sec) increased significantly to $209.77 \mathrm{mmHg} . \mathrm{cm} . \mathrm{sec}$ with sour stimulation $(p=0.000 ; 95 \% \mathrm{Cl},-86.97--31.81)$. A sour bolus did not significantly alter VCl, MCl, HPCl (Table 3).

Sour bolus significantly increased duration of UES opening (UESRT) from 0.58 secs to 0.68 secs during swallowing on $10 \mathrm{ml}$ fluids $(\mathrm{p}=0.027 ; 95 \% \mathrm{Cl},-.15--.01)$. Sour stimulation did not significantly alter IRP, UESBP or UES Peak P (see Table 4).

\section{Carbonation}

Global pharyngeal function (148.11 mmHg.cm.sec) increased significantly with a carbonated bolus to $187.40 \mathrm{mmhg} . \mathrm{cm} . \mathrm{sec}(\mathrm{p}=0.016 ; 95 \% \mathrm{Cl},-71.96--8.25)$.

Carbonation also significantly increased velopharyngeal vigor as measured by the $\mathrm{VCl}$ $(p=0.011 ; 95 \% \mathrm{Cl},-42.22--6.02)$ and mesopharyngeal vigor as measured by the $\mathrm{MCl}$ $(p=0.036 ; 95 \% \mathrm{Cl},-45.82--1.69) . \mathrm{HPCl}$ was not altered by carbonation (Table 3).

There was a statistically significant increase in duration of UES opening (UESRT) during swallowing with a carbonated bolus from 0.58 secs to 0.66 secs on $10 \mathrm{ml}$ fluids $(p=0.032 ; 95 \% \mathrm{Cl},-.15--.01)$. A carbonated bolus did not significantly alter IRP, UESBP or UES Peak P (see Table 4).

Table 4 here

\section{Discussion}


Limited evidence exists to date to support sensory stimulation as a dysphagia compensatory strategy in clinical practice. Previous research studies have been based mostly on VFS and have provided valuable information on changes in swallow safety, pharyngeal response time and pharyngeal residue with sensory stimulation. However, we have limited understanding of the effects of sensory stimulation on swallow physiology. In this study, the use of PHRM to evaluate the impact of sensory stimulation on swallowing physiology in adults with dysphagia was investigated for the first time.

One of the main findings in this study was that cold, sour and carbonation each caused a statistically significant increase in pharyngeal contraction vigour during the pharyngeal stage of swallowing in adults with dysphagia (see Figure 1). This finding supports the theory that sensory stimulation can alter swallow physiology beyond speeding up the pharyngeal swallow in people with dysphagia. The $\mathrm{PhCl}$ metric has been identified as a useful measure of global pharyngeal dysfunction and, unlike peak pressure metrics, it can capture sustained pressure generation in the pharynx. Based on previous research (20), $\mathrm{PhCl}$ scores were low in this participant group. Low $\mathrm{PhCl}$ scores have been linked to higher degrees of pharyngeal impairment and to higher aspiration scores (20). As a result, an increase in the $\mathrm{PhCl}$ during swallowing with sensory stimulation may improve aspiration status in adults with dysphagia.

In this study, carbonation was the only form of sensory stimulation which led to increased velopharyngeal and mesopharyngeal contractile integrals. It was interesting to note that, unlike velopharyngeal and mesopharyngeal contractile integrals, hypopharyngeal contractile integral $(\mathrm{HPCl})$ was not altered by any form of sensory stimulation in this study. It has been suggested that epiglottic inversion during 
swallowing can alter HPCI measures (4). Additionally, contractile integrals or pressure changes over space and time may not be as pertinent to the hypopharyngeal phase of swallowing compared to the velopharyngeal and mesopharyngeal stages.

Sensory stimulation also increased duration of UES opening during swallowing in this study which aligns with previous research. A needle EMG study previously found increased mylohyoid and anterior belly of the digastric muscle activity with a sour bolus compared to water in healthy adults (24). Similarly, surface electromyography (sEMG) studies have found increased duration of UES opening with a sour bolus in healthy adults $(25,26)$. Carbonation has been found to increase duration of UES opening in previous sEMG research (27). Additionally, research has found that carbonation reduces pharyngeal retention which may be linked to increased duration of UES opening (12). Interestingly, only the cold bolus significantly increased the extent of UES opening in this study based on the IRP metric. It could be possible that the method for calculating this metric could be influencing this finding (see Table 1). Use of maximum admittance based on impedance measures would be worthy of investigation in future research (4). No previous research was found evaluating the effect of cold on either duration or extent of UES opening as outcomes from previous research related to swallow safety, pharyngeal response time and pharyngeal retention (28).

\section{Figure 1 here}

The effects of a cold bolus on pressure measurements has not been investigated in previous PHRM research. A pressure drift has been observed in previous in vivo and in 
vitro research which can be caused by either a thermal effect (defined as an immediate change in pressure as the catheter temperature changes to body temperature at intubation) or a baseline drift (a linear drift in pressure across time) $(29,30)$. Corrective methods including thermal compensation and interpolated thermal composition have been developed to compensate for drift during HRM studies, the latter of which has been deemed beneficial (30).

The effects of a cold bolus on HRM pressure measures remains unclear. Numerous studies have investigated the effects of a cold bolus on esophageal motility using HRM $(33,34,35)$. In one study, twelve adults with achalasia completed HRM in a seated position and drank cold water at 2 degrees Celsius. No unwanted thermal effects on pressure measures were reported and HRM findings aligned with patient symptom reports (33). Another study evaluated cold water swallows (2 degrees Celsius) in 32 healthy adults and no thermal effects of the cold bolus were reported (34). In each of these esophageal studies, any unwanted immediate effects of a cold bolus on pressure measurements were not reported (31-33). It is purported that a cold bolus may not alter pressure measures as the temperature of the cold bolus may increase after the oral phase and by the time it contacts pressure sensors in the pharyno-esophageal region. Additionally, the contact time between the cold bolus and each of the pressure sensors is extremely brief making a thermal effect unlikely. Nevertheless, a specific PHR(I)M study to further evaluate this would be beneficial.

Findings have the potential to be of clinical significance as weak pharyngeal contraction has been associated with high aspiration rates during videofluoroscopy (20). Moreover, reduced duration of UES opening during swallowing has been associated with 
aspiration in adults with dysphagia (34). Previous research has also linked prolonged duration of UES opening during swallowing in adults with dysphagia with weak pharyngeal constriction during swallowing (35). It may be the case that while extent of UES opening during swallowing may be difficult to target in rehabilitation, duration of the UES opening may be more amenable to change to compensate for either neurological or age-related changes to swallow physiology to improve swallow safety and efficiency (35). The administration of sensory stimulation to a person with dysphagia to increase pharyngeal contraction vigour and to prolong duration of UES opening could be a viable intervention in clinical practice. There is a growing awareness of the lack of evidence to support safety and effectiveness of thickened fluids in people with dysphagia and of the low patient acceptability for thickened fluids (36). The emergence of a dysphagia intervention that has low cost and time constraints, low clinical risk and better patient acceptability certainly warrants further investigation.

\section{Study Limitations}

There were limitations to this exploratory study. Use of a pressure only catheter limited interpretation of findings from a bolus flow viewpoint. The inclusion of impedance data would provide valuable insight into changes in bolus flow occurring in response to sensory stimulation. While pressure captures the amount of squeeze on a pressure sensor at rest and during swallowing, impedance measures can calculate bolus clearance through the UES during swallowing and maximum admittance (inverse of nadir impedance) is correlated with sphincter cross-sectional area to provide a more direct measure of UES opening (37). A combined pressure-flow analysis would also 
allow metrics including intra-bolus pressure and swallow risk index (SRI) to be calculated.

Recent research has determined that catheter diameter can impact on swallowing measures (38). While a $4.2 \mathrm{~cm}$ diameter catheter is most commonly used in PHRM research (38), use of a smaller $(2.7 \mathrm{~cm})$ diameter catheter in future research may minimize effect of catheter presence on swallowing measures. The heterogeneous group was a limitation in this exploratory study as was the wide age range of participants given the effect of age on swallow pressures $(39,40)$. While a lack of control group was in keeping with this exploratory study, the inclusion of a control group should also be considered in future studies. The participants prescribed medication was not a focus of this study but medication has a known role in pharyngo-esophageal physiology and should be considered in future research.

\section{Conclusion}

This was the first study to use PHRM to evaluate the impact of sensory stimulation on pharyngo-esophageal swallowing in adults with dysphagia. Cold, sour and carbonated bolus increased pharyngeal contractile integrals and duration of UES opening during swallowing which has the potential to improve swallow safety and efficiency. Findings from this exploratory study provide new insights into sensory stimulation and suggest that sensory enhancement does more than speed up the pharyngeal swallow. This study contributes to the evidence base supporting sensory stimulation as a dysphagia intervention and serves as a basis for future research. 
Acknowledgements: Thanks to the members of the speech and language therapy department in Tallaght University Hospital for their support, to all participants who took part and to Sword Medical for their technical support.

\section{References}

1. Fox MR, Bredenoord AJ. (2008). Oesophageal high-resolution manometry: moving from research into clinical practice. Gut; 57:405-423.

2. Omari TI, Dejaeger E, van Beckevoort D, et al. (2011). A method to objectively assess swallow function in adults with suspected aspiration. Gastroenterology; 140: 1454-63

3. Omari TI, Dejeager E, Van Beckevoort D, Goeleven A, De Cock P, Hoffmen I, Smet MH, Davidson GP, Tack J, Rommel N. (2011). A novel method for the nonradiological assessment of ineffective swallowing. Am J Gastroenterol.106: 1796-802

4. Omari, T. I., Ciucci, M., Gozdzikowska, K., Hernández, E., Hutcheson, K., Jones, C., ... \& O'Rourke, A. (2019). High-Resolution Pharyngeal Manometry and Impedance: Protocols and Metrics-Recommendations of a High-Resolution Pharyngeal Manometry International Working Group. Dysphagia, 1-15

5. Hoffman, M. R., Ciucci, M. R., Mielens, J. D., Jiang, J. J., \& McCulloch, T. M. (2010). Pharyngeal swallow adaptations to bolus volume measured with high-resolution manometry. The Laryngoscope, 120(12), 2367-2373.

6. Lin, T., Xu, G., Dou, Z., Lan, Y., Yu, F., \& Jiang, L. (2014). Effect of bolus volume on pharyngeal swallowing assessed by high-resolution manometry. Physiology \& behavior, 128, 46-51.

7. Omari, T, Dejaeger, E, Tack, J, Van Beckevoort, D \& Rommel, N. (2013). "Effect of bolus volume and viscosity on pharyngeal automated impedance manometry variables derived for broad Dysphagia patients," Dysphagia, vol. 28, no. 2, pp. 146152.

8. Doeltgen, S. H., Ong, E., Scholten, I., Cock, C., \& Omari, T. (2017). Biomechanical quantification of Mendelsohn maneuver and effortful swallowing on 
pharyngoesophageal function. Otolaryngology-Head and Neck Surgery, 157(5), 816-823.

9. McCulloch, T. M., Hoffman, M. R., \& Ciucci, M. R. (2010). High-resolution manometry of pharyngeal swallow pressure events associated with head turn and chin tuck. Annals of Otology, Rhinology \& Laryngology, 119(6), 369-376.

10. Hoffman, M. R., Mielens, J. D., Ciucci, M. R., Jones, C. A., Jiang, J. J., \& McCulloch, T. M. (2012). High-resolution manometry of pharyngeal swallow pressure events associated with effortful swallow and the Mendelsohn maneuver. Dysphagia, 27(3), 418-426.

11. Logemann JA, Pauloski BR, Colangelo L, Lazarus C, Fujiu M, Kahrilas PJ. (1995). Effects of a sour bolus on oropharyngeal swallowing measures in patients with neurogenic dysphagia. J Speech Hear Res. 38:556-563.

12. Bulow M, Olsson R, Ekberg O. (2003). Videoradiographic analysis of how carbonated thin liquids and thickened liquids affect the physiology of swallowing in subjects with aspiration on thin liquids. Acta Radiol; 44:366-72.

13. . Sdravou K, Walshe M, Dagdilelis L. (2011). Effects of carbonated liquids on oropharyngeal swallowing measures in people with neurogenic dysphagia. Dysphagia. 27:1-11.

14. Turkington, L., Ward, E. C., Farrell, A., Porter, L. and Wall, L. R. (2019), Impact of carbonation on neurogenic dysphagia and an exploration of the clinical predictors of a response to carbonation. International Journal of Language \& Communication Disorders, 54: 499-513.

15. . Bisch, E. M., Logemann, J. A., Rademaker, A. W., Kahrilas, P. J., \& Lazarus, C. L. (1994). Pharyngeal effects of bolus volume, viscosity, and temperature in patients with dysphagia resulting from neurologic impairment and in normal subjects. Journal of Speech and Hearing Research, 37, 1041-1049.

16. . Dietsch, A., Solomon, N., Steele, C and Pelletier, C., (2014). The effect of barium on perceptions of taste intensity and palatability. Dysphagia, 29, 96- 108

17. . André, Jean (2001). Brain Stem Control of Swallowing: Neuronal Network and Cellular Mechanisms. Physiological Reviews 2001 81:2, 929-969. 
18. . Crary, M. A., Mann, G. D. C., \& Groher, M. E. (2005). Initial psychometric assessment of a functional oral intake scale for dysphagia in stroke patients. Archives of physical medicine and rehabilitation, 86(8), 1516-1520.

19. . Guiu Hernandez, E., Gozdzikowska, K., Apperley, O., \& Huckabee, M. L. (2018). Effect of topical nasal anesthetic on swallowing in healthy adults: A double-blind, high-resolution manometry study. The Laryngoscope, 128(6), 1335-1339.

20. O'Rourke, A., Humphries, K., Lazar, A., \& Martin-Harris, B. (2017). The pharyngeal contractile integral is a useful indicator of pharyngeal swallowing impairment. Neurogastroenterology \& Motility, 29(12), e13144.

21. Winiker, K., Gillman, A., Hernandez, E. G., Huckabee, M. L., \& Gozdzikowska, K. (2019). A systematic review of current methodology of high resolution pharyngeal manometry with and without impedance. European Archives of Oto-RhinoLaryngology, 276(3), 631-645.

22. . Omari TI, Savilampi J, Kokkinn K, Schar M, Lamvik K, Doeltgen S, Cock C. (2016). The reliability of pharyngeal high-resolution manometry with impedance and derivation of measures of swallowing function. Int J Otolaryngology.

23. Singendonk, M., Cock, C., Bieckmann, L., Szczesniak, M., Ferris, L., Benninga, M., \& Omari, T. (2018). Reliability of an online analysis platform for pharyngeal highresolution impedance manometry recordings. Speech, Language and Hearing, 1-9.

24. . Palmer PM, McCulloch TM, Jaffe D, Neel AT. (2005). Effects of a sour bolus on the intramuscular electromyographic (EMG) activity of muscles in the submental region. Dysphagia. 20:210-217.

25. Ding R, Logemann JA, Larson CR, Rademaker AW. (2003). The effects of taste and consistency on swallow physiology in younger and older healthy individuals: a surface electromyographic study. J Speech Hear Res.46:977-989.

26. . Leow, L. P., Huckabee, M. L., Sharma, S., \& Tooley, T. P. (2006). The influence of taste on swallowing apnea, oral preparation time, and duration and amplitude of submental muscle contraction. Chemical senses, 32(2), 119-128.

27. . Miura, Y., Yuji Morita, Hideki Koizumi, Tomio Shingai, (2009). Effects of Taste Solutions, Carbonation, and Cold Stimulus on the Power Frequency Content of 
Swallowing Submental Surface Electromyography, Chemical Senses; 34 (4): 325331.

28. . Cola P, Gatto A, Da Silva R, Spadotto A, Schelp A, Henr M. (2010). The influence of sour taste and cold temperature in pharyngeal transit duration in pharyngeal transit duration in patients with stroke. Arc Gastroenterol; 47:18-21.

29. . Robertson E, Lee Y, Derakhshan M, Wirz A, Whiting J, Seenan J, Connolly P, McColl KE. High-resolution esophageal manometry: addressing thermal drift of the manoscan system. Neurogastroenterol Motil 2012; 24: 61-5.

30. Lamvik, K., Guiu Hernandez, E., Jones, R., \& Huckabee, M. L. (2016).

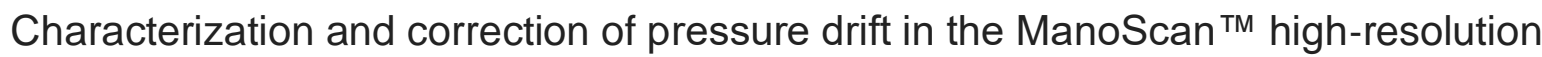
manometry system: In vitro and in vivo. Neurogastroenterology \& Motility, 28(5), 732-742.

31. Choi, Y. J., Park, M. I., Park, S. J., Moon, W, Kim, S. E., Kwon, H. J., Kim, J. H. and Jeon, W. S. (2014), The effect of water bolus temperature on esophageal motor function as measured by high-resolution manometry. Neurogastroenterol. Motil., 26: 1628-1634.

32. . Elvivi, A., Bravi, I., (2014). Effect of Cold Water on Esophageal Motility in Patients with Achalasia and Non-obstructive Dysphagia: A High-resolution Manometry Study. Neurogastroenterology and Motility; 20 (1): 79-86.

33. Ren Y, Ke M, Fang X, et al. (2012). Response of esophagus to high and low temperatures in patients with achalasia. J Neurogastroenterol Motility,18: 391-398.

34. Molfenter, S.M. \& Steele, C.M. (2014). Kinematic and Temporal Factors Associated with Penetration-Aspiration in Swallowing Liquids. Dysphagia, 29 (2): 269-276.

35. . Kendall KA, Leonard RJ. (2002). Videofluoroscopic upper esophageal sphincter function in elderly dysphagic patients. Laryngoscope. 2002;112(2):332-7.

36. Flynn, E., Smith, C. H., Walsh, C. D., \& Walshe, M. (2018). Modifying the consistency of food and fluids for swallowing difficulties in dementia. Cochrane Database of Systematic Reviews, (9)

37. . Cock, C., Jones, C.A., Hammer, M.J. et al. (2017). Modulation of Upper Esophageal Sphincter (UES) Relaxation and Opening During Volume Swallowing. Dysphagia, 32 (2); 216-224. 
38. . Ferris, L., Schar, M., McCall, L., Doeltgen, S., Scholten, I., Rommel, N., ... \& Omari, T. (2018). Characterization of swallow modulation in response to bolus volume in healthy subjects accounting for catheter diameter. The Laryngoscope, 128(6), 13281334.

39. Shaker, R. \& Lang, I. (1994). Effect of aging on the deglutitive oral, pharyngeal, and esophageal motor function. Dysphagia, 9, pp. 221-228.

40. . Nativ-Zeltzer, N., Logemann, J. A., Zecker, S. G., \& Kahrilas, P. J. (2016). Pressure topography metrics for high-resolution pharyngeal-esophageal manofluorography-a normative study of younger and older adults. Neurogastroenterology \& Motility, 28(5), 721-731. 


\section{Tables}

\section{Table 1. Definitions of PHRM Metrics}

\begin{tabular}{|c|c|c|}
\hline Metric & Unit & Definitions \\
\hline \multicolumn{3}{|r|}{ Pharyngeal Measures } \\
\hline $\begin{array}{l}\text { Pharyngeal } \\
\text { Contractile } \\
\text { Integral }\end{array}$ & mmHg.cm.sec & $\begin{array}{l}\text { Sum of pharyngeal pressures }>20 \mathrm{~mm} \mathrm{Hg} \text { from superior } \\
\text { pharyngeal constrictor margin to UES proximal margin over the } \\
\text { period from UES opening to } 0.5 \mathrm{~s} \text { after UES closure. }\end{array}$ \\
\hline $\begin{array}{l}\text { Velo- } \\
\text { pharyngeal } \\
\text { Contractile } \\
\text { Integral }\end{array}$ & mmHg.cm.sec & $\begin{array}{l}\text { Measure of contractile vigor within velopharyngeal region. } \mathrm{VCl} \text { is } \\
\text { mean pressure within this domain multiplied by duration and } \\
\text { length }\end{array}$ \\
\hline $\begin{array}{l}\text { Meso- } \\
\text { pharyngeal } \\
\text { Contractile } \\
\text { Integral }\end{array}$ & $\mathrm{mmHg} . \mathrm{cm} . \mathrm{sec}$ & $\begin{array}{l}\text { Measure of contractile vigor within mesopharyngeal region. } \mathrm{MCl} \\
\text { is mean pressure within this domain multiplied by duration and } \\
\text { length }\end{array}$ \\
\hline $\begin{array}{l}\text { Hypo- } \\
\text { pharyngeal } \\
\text { Contractile } \\
\text { Integral }\end{array}$ & mmHg.cm.sec & $\begin{array}{l}\text { Measure of contractile vigor within hypopharyngeal region. } \mathrm{HPCl} \\
\text { is mean pressure within this domain multiplied by duration and } \\
\text { length }\end{array}$ \\
\hline \multicolumn{3}{|r|}{ UES Measures } \\
\hline $\begin{array}{l}\text { UES } \\
\text { Relaxation } \\
\text { Time }\end{array}$ & seconds & $\begin{array}{l}\text { Measure of the duration of UES relaxation. It is the e-sleeve time } \\
\text { interval between pressure drop at UES } 50 \% \text { below baseline or } 35 \\
\mathrm{~mm} \mathrm{Hg} \text { (whichever is lower) }\end{array}$ \\
\hline $\begin{array}{l}\text { UES Integrated } \\
\text { Relaxation } \\
\text { Pressure }\end{array}$ & $\mathrm{mmHg}$ & $\begin{array}{l}\text { Measure of the extent of UES relaxation (based on UES } \\
\text { relaxation definition above and not on impedance or VFS). UES } \\
\text { IRP is the median of the lowest non-consecutive } 0.20-0.25 \\
\text { seconds of e-sleeve pressure }\end{array}$ \\
\hline $\begin{array}{l}\text { UES Basal } \\
\text { Pressure }\end{array}$ & $\mathrm{mmHg}$ & $\begin{array}{l}\text { Pre-swallow basal pressure in UES defined as average UES } \\
\text { profile pressure recorded over the period from } 1 \text { to } 0.25 \mathrm{~s} \text { prior to } \\
\text { UES opening. }\end{array}$ \\
\hline
\end{tabular}




\begin{tabular}{|l|l|l|}
\hline $\begin{array}{l}\text { UES post- } \\
\text { relaxation } \\
\text { Peak Pressure }\end{array}$ & $\mathrm{mmHg}$ & $\begin{array}{l}\text { UES post relaxation peak pressure defined as maximum UES } \\
\text { profile pressure recorded from } 0 \text { to } 1 \mathrm{~s} \text { after UES closure. }\end{array}$ \\
\hline
\end{tabular}

Table 2. Participant Demographics

\begin{tabular}{|c|c|c|c|c|}
\hline No & Gender & Age & Diagnosis & $\begin{array}{l}\text { Dysphagia } \\
\text { Severity } \\
\text { (Functional Oral } \\
\text { Intake Scale) }\end{array}$ \\
\hline 1 & Male & 70 & Stroke & 2 \\
\hline 2 & Male & 45 & Multiple Sclerosis & 5 \\
\hline 3 & Female & 86 & Stroke & 5 \\
\hline 4 & Male & 82 & $\begin{array}{l}\text { Motor neuron } \\
\text { disease }\end{array}$ & 4 \\
\hline 5 & Female & 61 & Unknown & 5 \\
\hline 6 & Female & 78 & $\begin{array}{l}\text { Motor neuron } \\
\text { disease }\end{array}$ & 3 \\
\hline 7 & Male & 62 & $\begin{array}{l}\text { Chronic obstructive } \\
\text { pulmonary disease }\end{array}$ & 5 \\
\hline 8 & Male & 58 & Lung cancer & 5 \\
\hline 9 & Male & 70 & Stroke & 4 \\
\hline 10 & Female & 56 & $\begin{array}{l}\text { Respiratory failure, } \\
\text { dysphagia }\end{array}$ & 5 \\
\hline 11 & Female & 55 & $\begin{array}{l}\text { Auto-immune } \\
\text { disease }\end{array}$ & 4 \\
\hline 12 & Female & 57 & $\begin{array}{l}\text { Gastro-esophageal } \\
\text { reflux disease, } \\
\text { dysphagia }\end{array}$ & 5 \\
\hline 13 & Male & 52 & Multiple sclerosis & 3 \\
\hline 14 & Female & 45 & $\begin{array}{l}\text { Unknown gastro- } \\
\text { intestinal disease, } \\
\text { dysphagia }\end{array}$ & 4 \\
\hline
\end{tabular}




\begin{tabular}{|l|l|l|l|l|}
\hline 15 & Male & 74 & Achalasia & 4 \\
\hline
\end{tabular}

Table 3. Pharyngeal Measures

\begin{tabular}{|c|c|c|c|c|c|c|c|c|}
\hline \multicolumn{9}{|c|}{ Pharyngeal Measures } \\
\hline $\begin{array}{l}\text { Baseline PhCl } \\
\text { (mmHg.cm.sec) }\end{array}$ & $\begin{array}{l}\text { Sensory } \\
\text { Stimulatio }\end{array}$ & $\mathrm{N}$ pairs & $\begin{array}{l}\text { Mean PhCl } \\
\text { (mmHg.cm.se }\end{array}$ & $\begin{array}{c}P \\
\text { value }\end{array}$ & SD & SEM & \multicolumn{2}{|c|}{$\begin{array}{c}\text { 95\% Cls } \\
\text { Lower Upper }\end{array}$} \\
\hline 148.11 & cold & 20 & 192.12 & $0.025^{*}$ & 83.11 & 18.58 & 84.24 & -6.44 \\
\hline 148.11 & sour & 26 & 209.77 & $0.000^{*}$ & 68.29 & 13.39 & 86.97 & -31.81 \\
\hline 148.11 & carbon & 22 & 187.40 & $0.016^{*}$ & 71.85 & 15.32 & 71.96 & -8.25 \\
\hline $\begin{array}{l}\text { Baseline VPI } \\
\text { (mmHg.cm.sec) }\end{array}$ & $\begin{array}{c}\text { Sensory } \\
\text { Stimulatio } \\
n\end{array}$ & $\begin{array}{c}\text { N pairs } \\
\text { of } \\
\text { swallow } \\
\text { s }\end{array}$ & $\begin{array}{c}\text { Mean VCI } \\
\text { (mmHg.cm.se } \\
\text { c) }\end{array}$ & $\begin{array}{c}\mathrm{P} \\
\text { value }\end{array}$ & SD & SEM & \multicolumn{2}{|c|}{$\begin{array}{c}\text { 95\% Cls } \\
\text { Lower Upper }\end{array}$} \\
\hline 66.67 & cold & 20 & 79.60 & 0.16 & 39.40 & 8.81 & 31.37 & 5.51 \\
\hline 66.67 & sour & 26 & 76.12 & 0.39 & 26.16 & 5.13 & $\begin{array}{l}- \\
15.03 \\
\end{array}$ & 6.10 \\
\hline 66.67 & carbon & 22 & 93.70 & $0.01^{*}$ & 40.83 & 8.70 & $\begin{array}{l}- \\
42.22 \\
\end{array}$ & -6.02 \\
\hline $\begin{array}{l}\text { Baseline MCl } \\
\text { (mmHg.cm.sec) }\end{array}$ & \begin{tabular}{|l|} 
Sensory \\
Stimulatio \\
$\mathbf{n}$
\end{tabular} & $\begin{array}{l}N \text { pairs } \\
\text { of } \\
\text { swallow } \\
\text { s }\end{array}$ & $\begin{array}{l}\text { Mean MCl } \\
\text { (mmHg.cm.se } \\
\text { c) }\end{array}$ & $\begin{array}{c}P \\
\text { value }\end{array}$ & SD & SEM & \multicolumn{2}{|c|}{$\begin{array}{c}95 \% \text { Cls } \\
\text { Lower Upper }\end{array}$} \\
\hline 69.21 & cold & 20 & 69.23 & 0.999 & 48.23 & 10.78 & $\begin{array}{l} \\
22.59 \\
\end{array}$ & 22.55 \\
\hline 69.21 & sour & 26 & 79.51 & 0.450 & 43.01 & 8.43 & $-\overline{23.85}$ & 10.89 \\
\hline 69.21 & carbon & 22 & 92.49 & $0.036^{*}$ & 49.76 & 10.61 & 45.82 & -1.69 \\
\hline $\begin{array}{l}\text { Baseline HPCl } \\
\text { (mmHg.cm.sec) }\end{array}$ & \begin{tabular}{|l|} 
Sensory \\
Stimulatio \\
$\mathbf{n}$
\end{tabular} & $\begin{array}{l}N \text { pairs } \\
\text { of } \\
\text { swallow } \\
\text { s }\end{array}$ & $\begin{array}{l}\text { Mean HPCl } \\
\text { (mmHg.cm.se } \\
\text { c) }\end{array}$ & $\begin{array}{c}P \\
\text { value }\end{array}$ & SD & SEM & \multicolumn{2}{|c|}{$\begin{array}{c}95 \% \text { Cls } \\
\text { Lower Upper }\end{array}$} \\
\hline
\end{tabular}




\begin{tabular}{|l|l|l|l|l|l|l|l|l|}
\hline 106.87 & cold & 20 & 87.46 & 0.14 & 56.92 & 12.73 & -7.23 & 46.04 \\
\hline 106.87 & sour & 26 & 105.06 & 0.37 & 46.99 & 9.21 & -10.63 & 27.33 \\
\hline 106.87 & carbon & 22 & 103.20 & 0.95 & 51.48 & 10.97 & -22.09 & 23.56 \\
\hline
\end{tabular}

Table 4. UES Measures

\begin{tabular}{|c|c|c|c|c|c|c|c|c|}
\hline \multicolumn{9}{|c|}{ UES Measures } \\
\hline $\begin{array}{c}\text { Baseline } \\
\text { UESRT } \\
\text { (secs) }\end{array}$ & $\begin{array}{c}\text { Sensory } \\
\text { Stimulation }\end{array}$ & $\begin{array}{l}\text { N swallow } \\
\text { pairs }\end{array}$ & $\begin{array}{l}\text { Mean } \\
\text { UESRT } \\
\text { (secs) }\end{array}$ & $P$ value & SD & SEM & \multicolumn{2}{|c|}{$\begin{array}{c}95 \% \text { Cls } \\
\text { Lower Upper }\end{array}$} \\
\hline 0.58 & cold & 20 & 0.69 & $0.041^{*}$ & .22 & .049 & -.21 & -.01 \\
\hline 0.58 & sour & 26 & 0.68 & $0.027^{*}$ & .175 & .034 & -.15 & -.01 \\
\hline 0.58 & carbonation & 22 & 0.66 & $0.032^{*}$ & .156 & .033 & -.15 & -.01 \\
\hline $\begin{array}{c}\text { Baseline } \\
\text { IRP } \\
\text { (mmHg) }\end{array}$ & $\begin{array}{l}\text { Sensory } \\
\text { Stimulation }\end{array}$ & $\begin{array}{l}\text { N swallow } \\
\text { pairs }\end{array}$ & $\begin{array}{c}\text { IRP } \\
(\mathrm{mmHg})\end{array}$ & $P$ value & SD & SEM & \multicolumn{2}{|c|}{$\begin{array}{c}95 \% \text { Cls } \\
\text { Lower Upper }\end{array}$} \\
\hline 7.74 & cold & 20 & 5.17 & $0.032^{*}$ & 8.09 & 1.81 & .39 & 7.97 \\
\hline 7.74 & sour & 26 & 7.77 & 0.649 & 8.14 & 1.59 & -2.55 & 4.02 \\
\hline 7.74 & carbonation & 22 & 7.63 & 0.686 & 10.68 & 2.28 & -3.80 & 5.67 \\
\hline $\begin{array}{l}\text { Baseline } \\
\text { UESPP } \\
\text { (mmHg) }\end{array}$ & $\begin{array}{l}\text { Sensory } \\
\text { Stimulation }\end{array}$ & $\begin{array}{c}\mathbf{N} \\
\text { swallow } \\
\text { pairs }\end{array}$ & $\begin{array}{l}\text { UESPP } \\
(\mathrm{mmHg})\end{array}$ & $P$ value & SD & SEM & \multicolumn{2}{|c|}{$\begin{array}{c}95 \% \text { Cls } \\
\text { Lower Upper }\end{array}$} \\
\hline 276.44 & cold & 20 & 248.42 & 0.215 & 73.4 & 16.4 & -13.3 & 55.4 \\
\hline 276.44 & sour & 26 & 283.81 & 0.587 & 70.3 & 13.8 & -35.9 & 20.8 \\
\hline 276.44 & carbonation & 22 & 275.97 & 0.745 & 85.7 & 18.3 & -31.97 & 44.01 \\
\hline
\end{tabular}




\begin{tabular}{|c|c|c|c|c|c|c|c|c|}
\hline $\begin{array}{c}\text { Baseline } \\
\text { UESBP } \\
(\mathbf{m m H g})\end{array}$ & $\begin{array}{c}\text { Sensory } \\
\text { Stimulation }\end{array}$ & $\begin{array}{c}\text { N } \\
\text { swallow } \\
\text { pairs }\end{array}$ & $\begin{array}{c}\text { UESBP } \\
(\mathbf{m m H g})\end{array}$ & P value & SD & \multicolumn{2}{|c|}{ SEM } & \multicolumn{2}{|c|}{$\begin{array}{c}95 \% \text { Cls } \\
\text { Lower Upper }\end{array}$} \\
\hline 71.27 & cold & 20 & 93.06 & 0.201 & 59.88 & 13.39 & -45.76 & 10.28 \\
\hline 71.27 & sour & 26 & 75.36 & 0.98 & 52.48 & 10.29 & -21.46 & 20.94 \\
\hline 71.27 & carbonation & 22 & 84.24 & 0.229 & 36.65 & 7.81 & -25.92 & 6.58 \\
\hline
\end{tabular}

Figure Legend

Figure 1

This figure captures the effect of sensory stimulation on duration of UES opening (UESRT) and extent of UES opening (UESIRP) in one participant (45-year-old male with multiple sclerosis). During a baseline $10 \mathrm{ml}$ liquid swallow (A), UES opening duration is 0.46 seconds and nadir pressure is $14.17 \mathrm{mmHg}$. During a sour $10 \mathrm{ml}$ liquid swallow (B), UES opening duration increases to 0.62 seconds but extent of UES opening does not decrease. With carbonation (C), UES opening duration is also increased ( 0.61 secs) compared to baseline $(0.46 \mathrm{secs})$ and extent of UES opening $(12.98 \mathrm{mmHg})$ is slightly decreased from baseline (14.17mHg). During cold bolus $10 \mathrm{ml}$ swallow (D), UES opening duration is 0.67 seconds and extent of UES opening drops to $7.32 \mathrm{mmHg}$.

Figure 1. Impact of sensory stimulation on extent and duration UES opening during $10 \mathrm{ml}$ liquid swallowing as measured by PHRM. 